\title{
Pressure-induced localized lipoatrophy
}

INSERM

\section{Source}

INSERM. (1999). Orphanet: an online rare disease and orphan drug data base. Pressureinduced localized lipoatrophy. ORPHA:90160

Pressure-induced localized lipoatrophy is a rare, acquired, localized lipodystrophy characterized by band-like, horizontal, asymptomatic, lipoatrophic depressions with clinically normal overlying skin usually involving the anterolateral aspect of the thighs. An identifiable history of the repeated mechanical microtrauma due to occupational or postural habits is present. 